\title{
Outcomes of Cardiogenic Shock Complicating Acute Coronary Syndromes
}

Short Title: Outcomes of Cardiogenic Shock

Authors: Dr Samer Noaman MBChB, ${ }^{1,2,3}$ Dr Nick Andrianopoulos MBBS MBiostat, ${ }^{4}$ Ms Angela L Brennan RN, ${ }^{4}$ Dr Diem Dinh MBBS ${ }^{4}$, Prof Christopher Reid MBBS, PhD, ${ }^{4,5}$ A/Prof Dion Stub MBBS, PhD, ${ }^{1,4}$ Dr Sinjini Biswas MBBS, ${ }^{1}$ A/Prof David Clark MBBS, ${ }^{6}$ Dr James Shaw MBBS, ${ }^{1,3} \mathrm{PhD}$, A/Prof Andrew Ajani MBBS, ${ }^{3}$ Dr Melanie Freeman MBBS, ${ }^{7}$ Dr Thomas Yip MBBS, ${ }^{8}$ A/Prof Ernesto Oqueli MBBS, ${ }^{9}$ A/Prof Antony Walton MBBS, ${ }^{1}$ Prof Stephen J Duffy MBBS, PhD, ${ }^{1,4}$ A/Prof William Chan MBBS, PhD, ${ }^{1,3,10}$ on behalf of the Melbourne Interventional Group Investigators.

${ }^{1}$ Department of Cardiology, Alfred Health, Victoria, Australia.

${ }^{2}$ Department of Medicine, University of Melbourne, Victoria, Australia.

${ }^{3}$ BakerIDI Heart and Diabetes Institute, Melbourne, Victoria, Australia

${ }^{4}$ Centre of Cardiovascular Research and Education in Therapeutics (CCRE), Department of Epidemiology and Preventive Medicine, Monash University, Victoria, Australia.

${ }^{5}$ School of Public Health, Curtin University, Perth, Western Australia, Australia.

${ }^{6}$ Department of Cardiology, Austin Health, Melbourne, Victoria, Australia.

${ }^{7}$ Department of Cardiology, Box Hill Hospital, Melbourne, Victoria, Australia.

${ }^{8}$ Department of Cardiology, Geelong University Hospital, Victoria, Australia.

${ }^{9}$ Department of Cardiology, Ballarat Health Services, Ballarat, Victoria, Australia.

${ }^{10}$ Monash University, Victoria, Australia

\section{Address for Correspondence / Corresponding Author:}

A/Prof William Chan, MBBS, PhD, FRACP.

Address: Alfred Hospital, 55 Commercial Road, Melbourne, VIC 3004

Email: william.chan@unimelb.edu.au

Ph: +61 390762000

This is the ahthor manuscript accepted for publication and has undergone full peer review but has not been through the copyediting, typesetting, pagination and proofreading process, which may lead to differences betweentaneous Coronary Intefvention (PCI) as doi: $10.1002 /$ ccdLE759eart Failure 
Word Count: 4,393

This article is protected by copyright. All rights reserved. 


\section{Outcomes of Cardiogenic Shock Complicating Acute Coronary Syndromes}

Short Title: Outcomes of Cardiogenic Shock

Authors: Dr Samer Noaman MBChB, ${ }^{1,2,3}$ Dr Nick Andrianopoulos MBBS MBiostat, ${ }^{4}$ Ms Angela L Brennan RN, ${ }^{4}$ Dr Diem Dinh $\mathrm{MBBS}^{4}$, Prof Christopher Reid MBBS, PhD, ${ }^{4,5}$ A/Prof Dion Stub MBBS, PhD, ${ }^{1,4}$ Dr Sinjini Biswas MBBS, ${ }^{1}$ A/Prof David Clark MBBS, ${ }^{6}$ Dr James Shaw MBBS, ${ }^{1,3} \mathrm{PhD}$, A/Prof Andrew Ajani MBBS, ${ }^{3}$ Dr Melanie Freeman MBBS, ${ }^{7} \mathrm{Dr}$ Thomas Yip MBBS, ${ }^{8}$ A/Prof Ernesto Oqueli MBBS, ${ }^{9}$ A/Prof Antony Walton MBBS, ${ }^{1}$ Prof Stephen J Duffy MBBS, PhD, ${ }^{1,4}$ A/Prof William Chan MBBS, PhD, ${ }^{1,3,10}$ on behalf of the Melbourne Interventional Group Investigators.

${ }^{1}$ Department of Cardiology, Alfred Health, Victoria, Australia.

${ }^{2}$ Department of Medicine, University of Melbourne, Victoria, Australia.

${ }^{3}$ BakerIDI Heart and Diabetes Institute, Melbourne, Victoria, Australia

${ }^{4}$ Centre of Cardiovascular Research and Education in Therapeutics (CCRE), Department of Epidemiology and Preventive Medicine, Monash University, Victoria, Australia.

${ }^{5}$ School of Public Health, Curtin University, Perth, Western Australia, Australia.

${ }^{6}$ Department of Cardiology, Austin Health, Melbourne, Victoria, Australia.

${ }^{7}$ Department of Cardiology, Box Hill Hospital, Melbourne, Victoria, Australia.

${ }^{8}$ Department of Cardiology, Geelong University Hospital, Victoria, Australia.

${ }^{9}$ Department of Cardiology, Ballarat Health Services, Ballarat, Victoria, Australia.

${ }^{10}$ Monash University, Victoria, Australia

\section{Address for Correspondence / Corresponding Author:}

A/Prof William Chan, MBBS, PhD, FRACP.

Address: Alfred Hospital, 55 Commercial Road, Melbourne, VIC 3004

Email: william.chan@unimelb.edu.au

Ph: +61 390762000 
Indexing Words: AMI - Acute myocardial infarction/STEMI

PCI - Percutaneous Coronary Intervention (PCI)

HF - Heart Failure

Word Count: 4,393

\section{Abstract}

Objectives: We aimed to assess the outcomes of Cardiogenic Shock (CS) complicating acute coronary syndromes (ACS).

Background: CS remains the leading cause of mortality in patients presenting with ACS despite advances in care.

Methods: We studied 13,184 patients undergoing percutaneous coronary intervention (PCI) for all subtypes of ACS enrolled prospectively in a large multicentre Australian registry (Melbourne Interventional Group registry) from 2005 to 2013. All-cause mortality was obtained via linkage to the National Death Index. Patients were divided into those with and those without CS.

Results: Compared to the non-CS group ( $n=12,548,95.2 \%)$, the CS group ( $n=636,4.8 \%$ ) had a higher proportion of out-of-hospital cardiac arrest (OHCA) (31.1\% vs. 2.2\%) and STelevation myocardial infarction (STEMI) presentation (89\% vs. 34\%), both $\mathrm{p}<0.01$. Patients in the CS group had higher rates of in-hospital (40.4\% vs. 1.2\%) and 30-day (41\% vs. 1.7\%) mortality compared to the non-CS group. Long-term mortality over a median follow-up of 4.2 years was higher in the CS group (50.6\% vs. $13.8 \%$ ), $\mathrm{p}<0.001$. Trends of in-hospital, and 30-day mortality rates of CS complicating ACS were relatively stable from 2005-2013. Predictors of long-term NDI-linked mortality within the CS group include severe left 
ventricular systolic dysfunction (HR 3.0), glomerular filtration rate (GFR) <30 (HR 2.56), GFR 30-59 (HR 1.94), OHCA (HR 1.46), diabetes (HR 1.44) and age (HR 1.02), all p<0.05.

Conclusions: Rates of CS-related mortality complicating ACS have remained very high and steady over nearly a decade despite progress in STEMI systems of care, PCI techniques and medical therapy.

\section{Introduction}

Cardiogenic shock (CS) complicates acute coronary syndrome (ACS) in approximately 5\% of patients and continues to carry a high mortality rate in excess of $40 \%$ to $50 \%(1,2)$ with historical rates of up to $90 \%$ prior to routine reperfusion therapy. (3) Despite advances in the management of acute myocardial infarction (MI) with timely reperfusion by primary percutaneous coronary intervention (PCI), CS remains the leading cause of in-hospital death among ACS patients. $(4,5)$ Early coronary revascularization was superior to initial medical stabilization with respect to early and late mortality outcomes in patients with CS in the landmark SHOCK trial. (6) Further efforts to reduce CS-related mortality using mechanical circulatory support devices such as intra-aortic balloon pump (IABP) or percutaneous left ventricular (LV) assist devices (for example, the Impella ${ }^{\circledR}$ ) have yielded conflicting results.

Multivessel disease is present in up to $80 \%$ of patients with CS complicating ACS. (6) While early revascularization improves outcomes of CS, immediate multivessel PCI was found to 
be associated with worse short- and medium-term outcomes compared to culprit-lesion-only PCI in the randomized CULPRIT-SHOCK trial. (8) The management of CS with multivessel coronary disease remains a contentious subject and requires further study.

Importantly, efforts to perform clinical research trials in patients with CS have been hindered by slow enrolment and difficulty with managing patients with CS. (9) Therefore, there remains an unmet need to obtain real-world data pertinent to current clinical practice and to report on trends in CS complicating ACS and survival over time. We aimed to analyze both short- and long-term clinical outcomes and trends in patients presenting with ACS complicated by CS treated by PCI.

\section{Methods}

\section{Study Design and Participants}

This study included consecutive patients who underwent PCI for ACS from 2005 to 2013, enrolled prospectively in the Melbourne Interventional Group (MIG) registry. The MIG registry is a multi-centre PCI registry and has been previously described in detail. $(10,11)$ Briefly, demographic, clinical, procedural and in-hospital outcome data are recorded on casereport forms using standardized definitions for all fields with telephone follow up and record review performed at 30 days and 12 months. (11)

The registry is coordinated by the Centre of Cardiovascular Research and Education in Therapeutics, an independent research body within the School of Public Health and Preventive Medicine at Monash University (Melbourne, Australia). There are 6 participating 
hospitals located in metropolitan Melbourne and regional Victoria, that all have 24-hour cardiac catheterization laboratory services. An audit of several verifiable fields from $5 \%$ of randomly selected procedures at each institution is undertaken periodically. $(11,12)$ In the most recent audit, 27 fields were assessed with data accuracy of 98\%, which compares favourably to audits from other large international registries. (13) The ethics committee in each participating hospital approved the MIG registry, including the use of “opt-out” consent. (10)

\section{Cardiogenic Shock and Clinical Outcomes Definitions}

Patients undergoing PCI for ACS were divided into two groups based on the presence or absence of CS prior to the PCI procedure. Cardiogenic shock was defined as a sustained episode of hypotension (systolic blood pressure $<90 \mathrm{mmHg}$ or vasopressors requirement to maintain blood pressure $>90 \mathrm{mmHg}$ ) for $>30$ minutes associated with evidence of elevated filling pressures such as pulmonary congestion in addition to the presence of end-organ hypoperfusion such as reduced urine output and altered mental status. Transient episodes of hypotension that were treated and corrected with intravenous fluids or chronotropic agents (such as atropine) were not included in the definition of CS.

Long-term all-cause mortality was obtained via linkage to the Australian National Death Index (NDI), which contains records of all deaths occurring in Australia since 1980. Data are obtained from the registries of births, deaths, and marriages in each state and territory. The following variables for each deceased patient were identified: name, date of birth (or 
estimated year of birth), age at death, gender, date of death, state/territory of registration, and registration number. Successful matching of patients through this linkage process was achieved in $99.42 \%$ of patients in the MIG registry. (14) Patients with missing NDI-linked data were excluded from the study.

The primary endpoint was long-term all-cause NDI-linked mortality. Secondary endpoints included in-hospital and 30-day major adverse cardiovascular events (MACE, a composite of all-cause mortality, myocardial infarction and target vessel revascularization). We also undertook subgroup analysis within the CS cohort based on PCI revascularization strategy (multivessel or single-vessel PCI) and the presenting ACS subtype (ST-elevation myocardial infarction [STEMI] versus no STEMI).

\section{Statistical Analysis}

Continuous variables were expressed as means \pm standard deviation (SD), and categorical variables were expressed as numbers/percentages, except where indicated. Continuous variables were compared using Student's t-tests or Kruskal-Wallis equality-of-populations rank test as appropriate. Categorical variables were compared using Pearson's chi-square test as appropriate. All calculated p-values were two-sided and p-values $<0.05$ were considered statistically significant.

Cumulative incidence of all-cause mortality was estimated by the Kaplan-Meier method, and the log-rank test was used to evaluate differences between groups. Cox proportional hazards 
modelling was used to identify univariate and multivariate predictors of NDI-linked mortality in those with CS. Univariate variables with a p-value $<0.10$ were then included in multivariate models using stepwise backward selection. In addition, we analyzed the temporal trends of in-hospital and 30-day mortality rates of CS complicating ACS as well as the trends of multivariable predictors of CS over the study period between 2005-2013. All statistical analyses were performed using Stata v14.1 for Windows (College Station, TX, USA). 


\section{Results}

\section{Patient Characteristics}

Of 13,184 patients who underwent PCI for ACS from 2005 to 2013, 636 (4.8\%) had CS at the time of PCI and 12,548 (95.2\%) comprised the non-CS group. Baseline characteristics of the two groups are presented in Table 1. Compared to the non-CS group, patients with CS were older (66.4 vs. 63.9 years) and had lower mean body mass index (26.7 vs. $28.3 \mathrm{~kg} / \mathrm{m}^{2}$ ) but had higher rates of peripheral vascular disease (PVD; 8.4\% vs. 5.9\%) and atrial fibrillation (AF; $16.1 \%$ vs. $5 \%$ ), all $\mathrm{p}<0.01$. Those with CS had worse baseline renal and LV systolic function and presented more frequently with out-of-hospital cardiac arrest (OHCA) (31.1\% vs. $2.2 \%)$ and STEMI (89\% vs. 34\%), all $\mathrm{p}<0.01$.

Table 2 summarizes the procedural characteristics in both groups. Patients in CS cohort had higher rates of femoral arterial access (96.2\% vs. 88.3\%) and had greater complexity and extent of coronary artery disease with higher proportion of multivessel coronary disease (70.1\% vs. 56.5\%), left main coronary artery (LMCA) disease ( $\geq 50 \%$ luminal stenosis; $22.2 \%$ vs. $6.4 \%$ ), and IABP utilization (58.3\% vs. $0.8 \%$ ) compared to the non-CS group, all $\mathrm{p}<0.01$. Post PCI Thrombolysis in Myocardial Infarction (TIMI) flow grade 3 was achieved in fewer patients in the CS group compared to the non-CS group (85.2\% vs. 95.8\%), and procedural success rates of revascularization were lower in those with CS (89.9\% vs. 96.8\%), both $\mathrm{p}<0.001$. Within the STEMI cohort, those patients with CS had longer median door-toballoon time (DTBT) (90 min IQR [60-121] vs. 79 min IQR [50-114], p<0.001), but shorter 
overall symptom-to-balloon time (STBT) (192 min IQR [145-286] vs. 206 min IQR [148324], $\mathrm{p}<0.05$ ) compared to the non-CS group.

\section{Clinical Outcomes}

Patients in the CS group had higher rates of in-hospital and 30-day all-cause mortality, cardiac mortality and MACE compared to the non-CS group, all $\mathrm{p}<0.001$ (Table 3). Inhospital and 30-day complications were also higher among the CS group including target vessel revascularization, target lesion revascularization and stroke, all $\mathrm{p}<0.001$. There were also lengthier in-hospital stays and greater readmissions at 30 days in the CS group, both $\mathrm{p}<0.001$. Long-term NDI-linked mortality was higher in the CS group compared to the nonCS group (50.6\% vs. $13.8 \%$, $\mathrm{p}<0.001)$ over a median follow up of 4.2 years. Kaplan-Meier survival curves underscored the early divergence, especially within the first 30 days, of survival over time in those with CS in contrast to those without CS, $\mathrm{p}<0.01$ (see Figure 1). Yearly trends of in-hospital and 30-day mortality rates of the CS group are shown in Figure 2, which demonstrate relatively stable rates over 2005-2013 ranging between $31 \%$ and $51 \%$.

\section{Predictors of Outcomes}

Cox proportional hazards regression analysis for long-term NDI-linked mortality within the CS group identified severe LV systolic dysfunction (LV ejection fraction $<30 \%$; HR 3.0, 95\% CI 2.03-4.43), glomerular filtration rate (GFR) $<30 \mathrm{~mL} / \mathrm{min}$ per $1.73 \mathrm{~m}^{2}$ (HR 2.56, 95\% CI 1.7-3.85), GFR 30-59 mL/min per $1.73 \mathrm{~m}^{2}$ (HR 1.94, 95\% CI 1.43-2.62), OHCA (HR 1.46, 95\% CI 1.1-1.95), diabetes (HR 1.44, 95\% CI 1.08-1.92) and age (per year increase) 
(HR 1.02, 95\% CI 1.01-1.04) to be the independent predictors of adverse outcome, all $\mathrm{p}<0.05$ (Table 5). The univariate predictors of NDI-linked mortality that were included in the multivariate analysis are shown in the supplementary material. Figure 3 depicts yearly rates of the independent predictors within the CS group for long-term NDI-linked mortality. The prevalence of these independent predictors over the decade appeared relatively constant except for OHCA, and ranged from 11\% to 33\% for LV systolic dysfunction, $7 \%$ to $14 \%$ for GFR $<30 \mathrm{~mL} / \mathrm{min}$ per $1.73 \mathrm{~m}^{2}, 42 \%$ to $56 \%$ for GFR $30-50 \mathrm{~mL} / \mathrm{min}$ per $1.73 \mathrm{~m}^{2}, 19 \%$ to $32 \%$ for diabetes and a mean age of 63 to 68 years. The rates of OHCA presentation to hospital ranged between $13 \%$ to $15 \%$ between 2005 and 2007 and increased to $31 \%$ to $44 \%$ between 2008 and 2013.

\section{Subgroup Analyses}

Subgroup analysis within the CS cohort revealed poorer long-term survival among those who underwent multivessel PCI as well as those who presented with ACS other than STEMI as shown in the Kaplan-Meier survival curves in Figure 1. In-hospital and 30-day mortality and MACE rates for those subgroups are shown in Table 5. Patients who had CS and underwent left main coronary artery PCI had higher long-term mortality compared to those with non-left main coronary artery PCI (Kaplan-Meier survival curves are provided in the supplementary material). There was no significant difference in the group of patients who received IABP support compared to those without IABP support in the CS cohort (Kaplan-Meier survival curves provided in the supplementary material). 


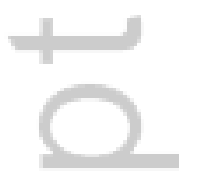

This article is protected by copyright. All rights reserved. 


\section{Discussion}

In this large, multi-centre Australian PCI registry, mortality from CS complicating ACS at any time point following PCI, but particularly within the first 30 days, remained high ( 40\%) despite routine timely mechanical reperfusion, and contemporary medical therapy. The steady in-hospital mortality rate of $\sim 40 \%$ in the CS group over a period of 8 years underscores the profound negative impact of CS on survival among those with ACS undergoing PCI and highlights the unmet clinical need for effective therapeutic strategies to improve in-hospital and short-term survival. To our knowledge, ours is one of the few studies that have evaluated long-term outcomes and mortality trends of CS in ACS over a period close to a decade in the contemporary PCI, STEMI care, and medical therapy era. (1)

Among patients with ACS undergoing PCI, those with CS had greater in-hospital, 30-day, and long-term NDI-linked mortality compared to the non-CS group. There are several explanations for this observation. Firstly, the CS group of patients were older and had greater rates of cardiovascular comorbidities such as PVD, AF, worse renal and LV systolic function, and, in addition, were more often presenting with OHCA and STEMI compared to the nonCS group. In the NCDR report by Anderson et al, CS complicated 12.2\% of the STEMI and 4.3\% of the NSTEMI groups with STEMI representing 65\% of the CS cohort. (15) Ostenfeld et al reported a similar prevalence of OHCA presentation in the CS population secondary to myocardial infarction. (16) Secondly, the CS cohort had greater complexity of procedural characteristics as reflected by the higher rates of LMCA disease, culprit LMCA PCI and complex type B2/C lesions compared to the non-CS group. These findings are in accord with 
other CS studies. $(5,17)$ Furthermore, following PCI the CS group had significantly higher rates of both transient and persistent no-reflow likely due to the higher prevalence of STEMI/OHCA PCI coupled with complex lesion characteristics as described in previous studies. $(4,5)$ The significance of no-reflow and its independent adverse impact on outcomes have been well described. (18) Among the STEMI CS subgroup, only 49.4\% of these patients achieved a target door-to-balloon time (DTBT) of $\leq 90$ minutes compared to $59 \%$ in non-CS group. Similar rates of DTBT were reported in a study by Kawaji et al with only $46.6 \%$ of STEMI patients complicated by CS achieving the guideline-recommended target DTBT. (19) The longer DTBT is likely due to the more complex resuscitation needs of patients presenting with STEMI and CS. The specific impact of delayed revascularization in STEMI CS patients is difficult to quantify but likely significant given the well-described relationship between outcomes and DTBT in STEMI. (20)

Following 30 days, the survival KM curves between the CS and non-CS groups appear to parallel each other during long-term follow up. This finding of time-dependent mortality risk is consistent with other CS studies. $(21,22)$ A study by Shah et al from the ACTION registry reported outcomes in survivors of CS and described an increased risk of mortality in the early period following hospital discharge with higher rates of unadjusted and adjusted mortality in the CS survivors compared to non-CS survivors at 60 days (adjusted HR 1.62, 95\% CI 1.41.8), however similar mortality to non-CS survivors up to one year (adjusted HR 1.08, 95\% CI 1.0-1.1). (21) In the FAST-MI registry, there was an independent association of CS with risk of death at 12 months (adjusted HR 2.87, 95\% CI 1.8-4.4) compared to the non-CS 
group, however this association was not evident at 5 years (adjusted HR 1.06, 95\% CI 0.61.7). (22) These studies along with our findings suggest that survival beyond the index hospitalization and the first year among CS and no CS patients is likely as a result of secondary prevention therapy, and the effect of revascularization.

\section{Trends of CS and Outcomes}

Yearly in-hospital and 30-day mortality rates of the CS group have remained relatively stable ranging from 31\% and up to 51\% between 2005 and 2013. The trends of the predictors of mortality in the CS cohort, namely diabetes, renal impairment, LV dysfunction, OHCA and older age, also remained relatively stable across almost a decade, except for an increased rate of OHCA presentation since 2008. Although speculative, it is possible that the increased rate of OHCA presentation since 2008 could simply reflect greater willingness of participating hospitals to treat OHCA associated CS with revascularization, and not an actual increase incidence of OHCA presentation per se. Apart from the routine early revascularization paradigm in CS following the SHOCK trial, (6) there have been no other recent effective therapeutic interventions to reduce mortality in CS as reflected by the static mortality rates of $\sim 40-50 \%$ since 1999. Specifically, routine use of IABP showed no short- or long-term mortality benefit in the IABP-SHOCK II randomized trial. (23) In our study, the proportion of CS patients treated with IABP was significantly higher than the non-CS cohort (58.3\% vs. $0.8 \%, \mathrm{p}<0.001)$. However, IABP use was not an independent predictor of mortality in multivariable analysis. Other promising percutaneous mechanical circulatory support systems such as the Impella ${ }^{\circledR}$ have been compared to IABP in a randomized clinical trial of patients 
with predominantly cardiac arrest complicated by CS showing a lack of difference in 30-day mortality likely due to small numbers of enrolled patients. (24)

\section{Predictors of Long-Term Mortality}

Among the adverse independent predictors (see Table 4), LV systolic dysfunction had the highest hazard ratio, a finding also confirmed by a sub-study of the SHOCK trial, (6) in which a median LV ejection fraction of $<28 \%$ was independently associated with 30-day or 1-year mortality. (25) Renal impairment at baseline has also been consistently reported to be associated with mortality. (26) The effect of OHCA on mortality is well known (27) and in the context of CS is likely to compound the mortality hazard. $(28,29)$ Our finding of older age as an independent predictor of poorer outcomes in CS has also been reported in other studies. $(26,30)$

\section{Subgroups Analysis}

In a subgroup analysis of CS patients undergoing multivessel versus single-vessel PCI, we observed similar rates of in-hospital and 30-day all-cause mortality, however, long-term NDIlinked mortality was higher in those who had multivessel PCI $(62.5 \%$ vs. $49 \%, \mathrm{p}=0.031)$. This finding is similar to the result reported in the CULPRIT-SHOCK trial. $(8,31)$ These observations suggest that immediate complete revascularization of AMI CS could be detrimental in the short-term with a potential long-term legacy effect as well. $(8,31)$ Conversely, in the Korean KAMIR-NIH registry investigating the impact of multivessel PCI versus culprit-lesion only PCI in 659 patients with STEMI complicated by CS, (32) the 
multivessel PCI group had a reduced risk of 1-year all-cause death (21.3\% vs. 31.7\%, $\mathrm{p}<0.01$ ), and multivessel PCI was independently associated with reduced risk of all-cause death at 1 year follow up (HR 0.59, 95\% CI 0.43-0.82, p=0.01). The discrepancy between the results of the two studies might be due to different study design; and timing of PCI in the multivessel PCI group, which was mandated upfront during the index procedure in CULPRIT-SHOCK.

In our study, we observed a higher in-hospital, 30-day and long-term mortality in the subgroup of patients with CS presenting with ACS other than STEMI compared to those with STEMI (62.9\% vs. $37.6 \%$, $64.3 \%$ vs. $38.2 \%$ and $78.6 \%$ vs. $47.2 \%$, all $\mathrm{p}<0.01$ respectively). This finding has been similarly described by Anderson et al who reported higher rates of comorbidities in patients with CS and ACS other than STEMI, which could contribute to the higher in-hospital mortality compared to those with CS and STEMI. (15)

\section{Clinical Implications and Future Directions}

Our study findings highlight the critical need for more effective therapeutic approaches to improve the persistently high mortality of CS complicating ACS. In line with recommendations from American Heart Association, (33) we also advocate for streamlined prehospital systems of care utilizing a Hub and Spoke model with establishment of Spoke Centres capable of implanting temporary mechanical circulatory support devices and Hub Centres capable of providing cardiac surgery, LV assist devices and cardiac transplantation, as exemplified by the success of the Detroit CS Initiative and National CS Initiative. (34) In 
our study, the longer DTBT in the CS group compared to the non-CS group was likely due to complex resuscitation needs of the CS cohort, which could undermine the therapeutic benefits of revascularization. This delay period to revascularization could be minimized with earlier recognition of CS and streamlining of transport and resuscitation to the catheterization laboratory with a specialized CS team.

\section{Limitations}

Our study results are subject to several limitations. This was a retrospective, observational analysis of patients enrolled prospectively in a large PCI registry, and therefore, inherent selection bias for PCI as well as inability to adjust for unmatched differences in all confounders could have impacted on outcomes. We only analyzed CS patients who underwent PCI and did not include those treated with medical management or surgical revascularization. Our study period was from 2005-2013 so the trends, procedural characteristics and clinical outcomes of CS and non-CS patients reflect the management of CS during this period only. Details of post-procedural care including intensive care treatment, vasopressor/inotropic utilization, mechanical support devices other than IABP were not captured. Similarly, we did not collect data regarding non-cardiac organ failure which could influence outcomes given the adverse prognostic role of non-cardiac organ failure in the CS population. (35) Lastly, we did not record outcomes such as withdrawal of end-of-life care, withdrawal of non-cardiac organ support, heart failure admissions and recurrent myocardial infarctions during long-term follow-up. 


\section{Conclusions}

The mortality of CS, especially in-hospital, remained persistently high in excess of $40 \%$ over an 8-year period despite current systems of care with routine timely mechanical reperfusion and contemporary medical therapy. Patients presenting with ACS complicated by CS represent a very high-risk patient subset with greater comorbidities, coronary artery disease complexity, and longer DTBT. Beyond 30 days, mortality of CS survivors appeared similar to non-CS patients, underscoring the unmet need for efforts to improve short-term survival in this group of patients.

This article is protected by copyright. All rights reserved. 


\section{Abbreviations}

CS - Cardiogenic Shock

PCI - Percutaneous Coronary Intervention

ACS - Acute Coronary Syndrome

STEMI - ST-Elevation Myocardial Infarction

This article is protected by copyright. All rights reserved. 


\section{References}

1. De Luca L, Olivari Z, Farina A et al. Temporal trends in the epidemiology, management, and outcome of patients with cardiogenic shock complicating acute coronary syndromes. European journal of heart failure 2015;17:1124-32.

2. Hunziker L, Radovanovic D, Jeger R et al. Twenty-Year Trends in the Incidence and Outcome of Cardiogenic Shock in AMIS Plus Registry. Circ Cardiovasc Interv 2019;12:e007293.

3. Goldberg RJ, Gore JM, Alpert JS et al. Cardiogenic shock after acute myocardial infarction. Incidence and mortality from a community-wide perspective, 1975 to 1988. The New England journal of medicine 1991;325:1117-22.

4. Kolte D, Khera S, Aronow WS et al. Trends in incidence, management, and outcomes of cardiogenic shock complicating ST-elevation myocardial infarction in the United States. Journal of the American Heart Association 2014;3:e000590.

5. Wayangankar SA, Bangalore S, McCoy LA et al. Temporal Trends and Outcomes of Patients Undergoing Percutaneous Coronary Interventions for Cardiogenic Shock in the Setting of Acute Myocardial Infarction: A Report From the CathPCI Registry. JACC Cardiovascular interventions 2016;9:341-351.

This article is protected by copyright. All rights reserved. 
6. Hochman JS, Sleeper LA, Webb JG et al. Early revascularization in acute myocardial infarction complicated by cardiogenic shock. SHOCK Investigators. Should We Emergently Revascularize Occluded Coronaries for Cardiogenic Shock. The New England journal of medicine 1999;341:625-34.

7. Seyfarth M, Sibbing D, Bauer I et al. A randomized clinical trial to evaluate the safety and efficacy of a percutaneous left ventricular assist device versus intra-aortic balloon pumping for treatment of cardiogenic shock caused by myocardial infarction. Journal of the American College of Cardiology 2008;52:1584-8.

8. Thiele H, Akin I, Sandri M et al. One-Year Outcomes after PCI Strategies in Cardiogenic Shock. The New England journal of medicine 2018.

9. Ouweneel DM, Engstrom AE, Sjauw KD et al. Experience from a randomized controlled trial with Impella 2.5 versus IABP in STEMI patients with cardiogenic preshock. Lessons learned from the IMPRESS in STEMI trial. Int J Cardiol 2016;202:894-6.

10. Ajani AE, Szto G, Duffy SJ et al. The foundation and launch of the Melbourne Interventional Group: a collaborative interventional cardiology project. Heart Lung Circ 2006;15:44-7.

11. Chan W, Clark DJ, Ajani AE et al. Progress towards a National Cardiac Procedure Database--development of the Australasian Society of Cardiac and Thoracic Surgeons (ASCTS) and Melbourne Interventional Group (MIG) registries. Heart, lung \& circulation 2011;20:10-8. 
12. Andrianopoulos N, Dinh D, Duffy SJ et al. Quality control activities associated with registries in interventional cardiology and surgery. Heart, lung \& circulation 2011;20:180-6.

13. Lagerqvist B, James SK, Stenestrand U, Lindback J, Nilsson T, Wallentin L. Longterm outcomes with drug-eluting stents versus bare-metal stents in Sweden. The New England journal of medicine 2007;356:1009-19.

14. Biswas S, Andrianopoulos N, Papapostolou S et al. Does the subtype of acute coronary syndrome treated by percutaneous coronary intervention predict long-term clinical outcomes? Eur Heart J Qual Care Clin Outcomes 2018;4:318-327.

15. Anderson ML, Peterson ED, Peng SA et al. Differences in the profile, treatment, and prognosis of patients with cardiogenic shock by myocardial infarction classification: A report from NCDR. Circ Cardiovasc Qual Outcomes 2013;6:708-15.

16. Ostenfeld S, Lindholm MG, Kjaergaard J et al. Prognostic implication of out-ofhospital cardiac arrest in patients with cardiogenic shock and acute myocardial infarction. Resuscitation 2015;87:57-62.

17. Trzeciak P, Gierlotka M, Gasior M et al. Mortality of patients with ST-segment elevation myocardial infarction and cardiogenic shock treated by PCI is correlated to the infarct-related artery--results from the PL-ACS Registry. Int J Cardiol 2013;166:193-7.

18. Papapostolou S, Andrianopoulos N, Duffy SJ et al. Long-term clinical outcomes of transient and persistent no-reflow following percutaneous coronary intervention (PCI): a multicentre Australian registry. EuroIntervention : journal of EuroPCR in 
collaboration with the Working Group on Interventional Cardiology of the European Society of Cardiology 2018;14:185-193.

19. Kawaji T, Shiomi H, Morimoto T et al. Long-term clinical outcomes in patients with ST-segment elevation acute myocardial infarction complicated by cardiogenic shock due to acute pump failure. Eur Heart J Acute Cardiovasc Care 2018;7:743-754.

20. Kochar A, Al-Khalidi HR, Hansen SM et al. Delays in Primary Percutaneous Coronary Intervention in ST-Segment Elevation Myocardial Infarction Patients Presenting With Cardiogenic Shock. JACC Cardiovascular interventions 2018;11:1824-1833.

21. Shah RU, de Lemos JA, Wang TY et al. Post-Hospital Outcomes of Patients With Acute Myocardial Infarction With Cardiogenic Shock: Findings From the NCDR. Journal of the American College of Cardiology 2016;67:739-47.

22. Aissaoui N, Puymirat E, Simon T et al. Long-term outcome in early survivors of cardiogenic shock at the acute stage of myocardial infarction: a landmark analysis from the French registry of Acute ST-elevation and non-ST-elevation Myocardial Infarction (FAST-MI) Registry. Crit Care 2014;18:516.

23. Thiele H, Zeymer U, Thelemann N et al. Intraaortic Balloon Pump in Cardiogenic Shock Complicating Acute Myocardial Infarction: Long-Term 6-Year Outcome of the Randomized IABP-SHOCK II Trial. Circulation 2018.

24. Ouweneel DM, Eriksen E, Sjauw KD et al. Percutaneous Mechanical Circulatory Support Versus Intra-Aortic Balloon Pump in Cardiogenic Shock After Acute

This article is protected by copyright. All rights reserved. 
Myocardial Infarction. Journal of the American College of Cardiology 2017;69:278287.

25. Picard MH, Davidoff R, Sleeper LA et al. Echocardiographic predictors of survival and response to early revascularization in cardiogenic shock. Circulation 2003;107:279-84.

26. Klein LW, Shaw RE, Krone RJ et al. Mortality after emergent percutaneous coronary intervention in cardiogenic shock secondary to acute myocardial infarction and usefulness of a mortality prediction model. The American journal of cardiology 2005;96:35-41.

27. Wong MK, Morrison LJ, Qiu F et al. Trends in short- and long-term survival among out-of-hospital cardiac arrest patients alive at hospital arrival. Circulation 2014;130:1883-90.

28. Vergara R, Valenti R, Migliorini A et al. A New Risk Score to Predict Long-Term Cardiac Mortality in Patients With Acute Myocardial Infarction Complicated by Cardiogenic Shock and Treated With Primary Percutaneous Intervention. The American journal of cardiology 2017;119:351-354.

29. Lim HS, Stub D, Ajani AE et al. Survival in patients with myocardial infarction complicated by out-of-hospital cardiac arrest undergoing emergency percutaneous coronary intervention. Int J Cardiol 2013;166:425-30.

30. Zeymer U, Vogt A, Zahn R et al. Predictors of in-hospital mortality in 1333 patients with acute myocardial infarction complicated by cardiogenic shock treated with primary percutaneous coronary intervention (PCI); Results of the primary PCI registry

This article is protected by copyright. All rights reserved. 
of the Arbeitsgemeinschaft Leitende Kardiologische Krankenhausarzte (ALKK). European heart journal 2004;25:322-8.

31. Thiele H, Akin I, Sandri M et al. PCI Strategies in Patients with Acute Myocardial Infarction and Cardiogenic Shock. The New England journal of medicine 2017;377:2419-2432.

32. Lee JM, Rhee TM, Hahn JY et al. Multivessel Percutaneous Coronary Intervention in Patients With ST-Segment Elevation Myocardial Infarction With Cardiogenic Shock. Journal of the American College of Cardiology 2018;71:844-856.

33. van Diepen S, Katz JN, Albert NM et al. Contemporary Management of Cardiogenic Shock: A Scientific Statement From the American Heart Association. Circulation 2017;136:e232-e268.

34. Basir MB, Schreiber T, Dixon S et al. Feasibility of early mechanical circulatory support in acute myocardial infarction complicated by cardiogenic shock: The Detroit cardiogenic shock initiative. Catheterization and cardiovascular interventions : official journal of the Society for Cardiac Angiography \& Interventions 2018;91:454-461.

35. Vallabhajosyula S, Dunlay SM, Prasad A et al. Acute Noncardiac Organ Failure in Acute Myocardial Infarction With Cardiogenic Shock. Journal of the American College of Cardiology 2019;73:1781-1791.

This article is protected by copyright. All rights reserved. 


\section{Figures}

Figure 1. Kaplan Meier estimate curves for the long-term NDI-linked mortality in the CS and the non-CS groups (a) and subgroups of CS patients (b).

Figure 2. Yearly trends of in-hospital and 30-day mortality of the CS group.

Figure 3. Yearly trends of the independent predictors of NDI-linked mortality of the CS group. eGFR, estimated Glomerular Filtration Rate; EF, Ejection Fraction; OHCA, Out-of-Hospital Cardiac Arrest. 


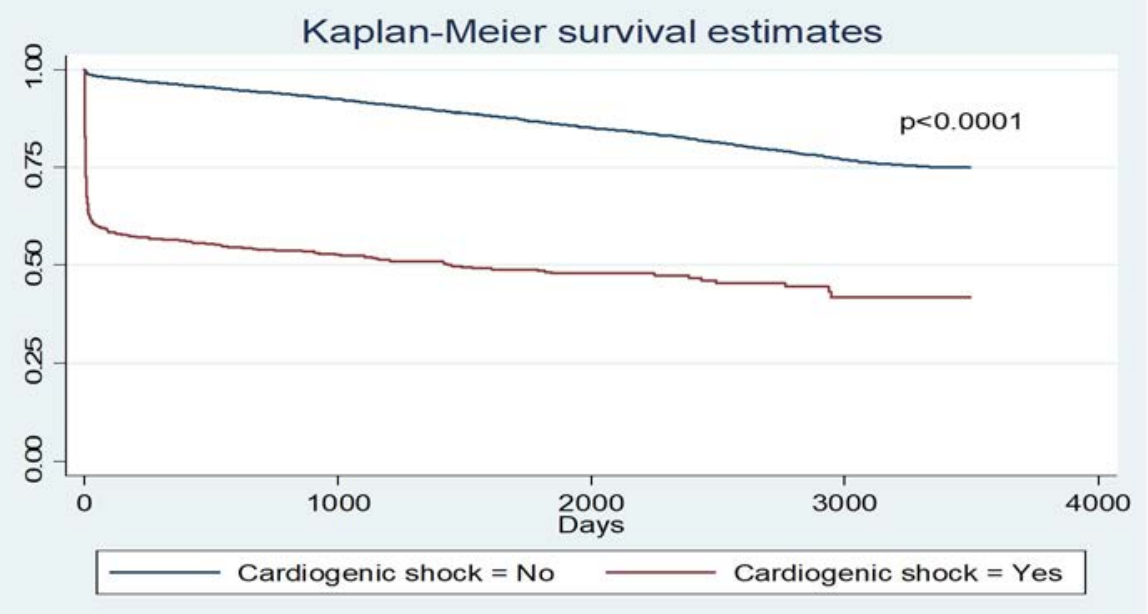

a
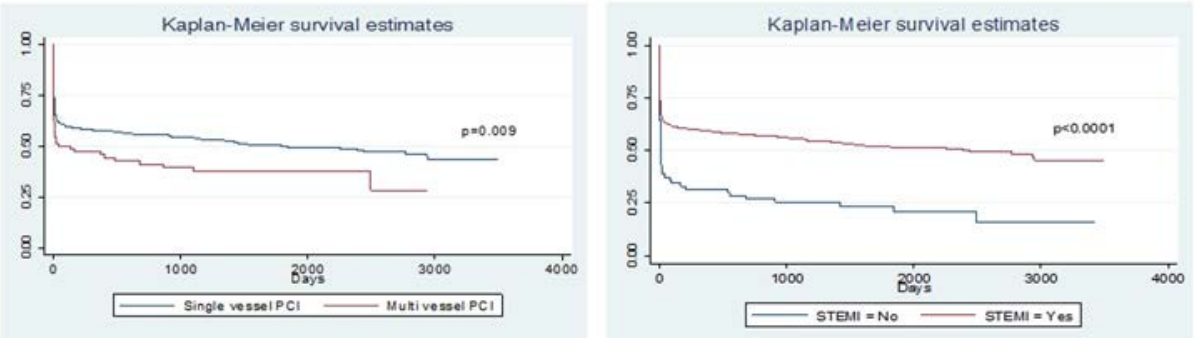

b

This article is protected by copyright. All rights reserved. 


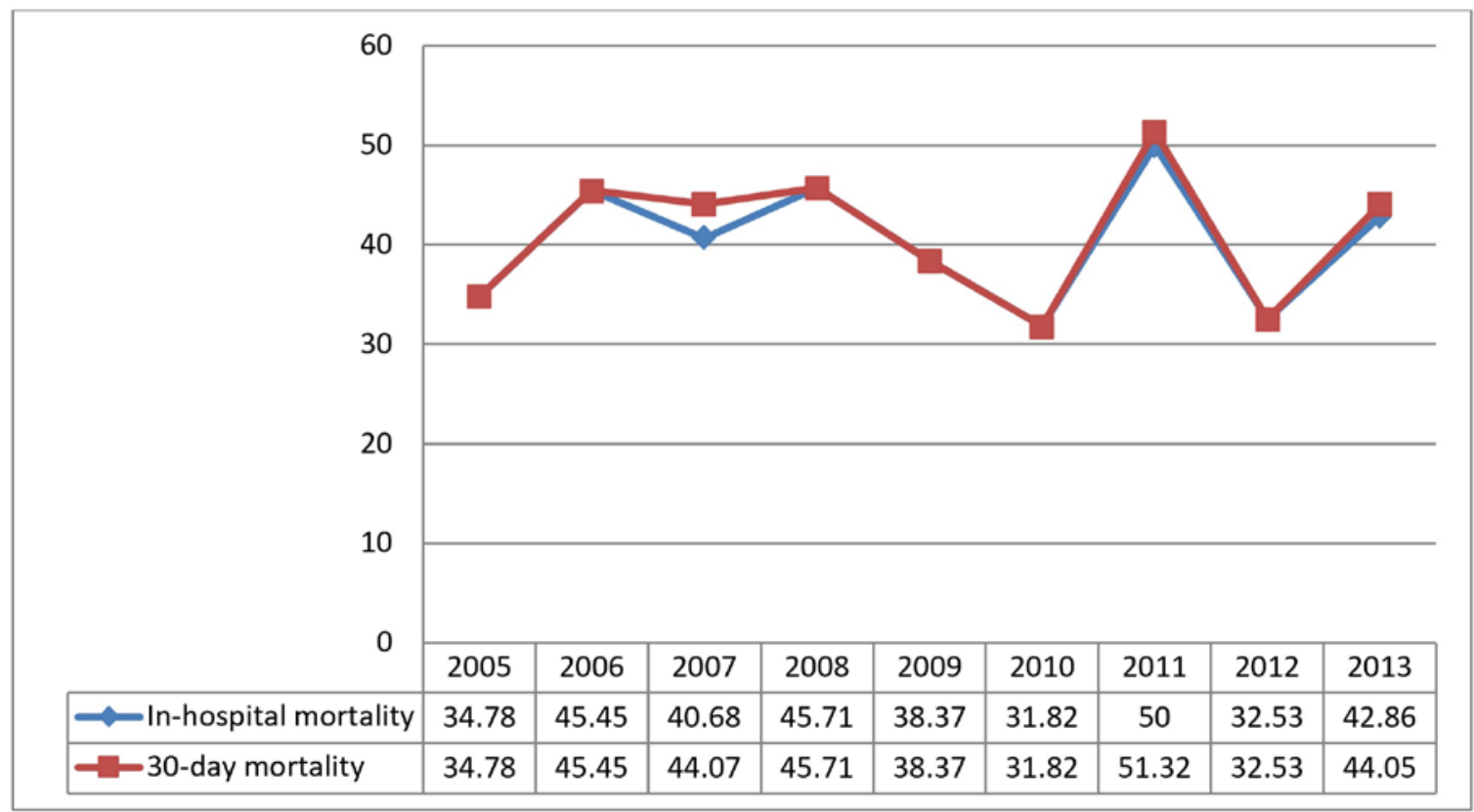

This article is protected by copyright. All rights reserved. 


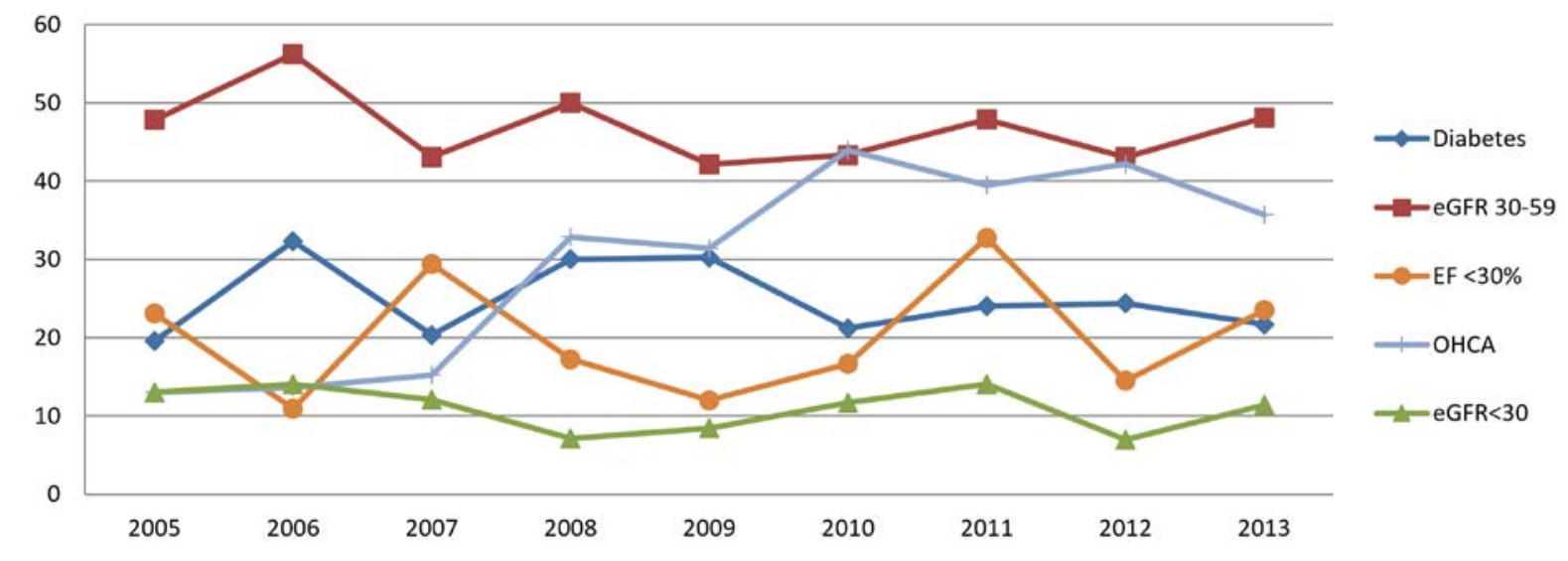

This article is protected by copyright. All rights reserved. 
Table 1. Baseline demographic and clinical characteristics of patients with ACS undergoing $\mathrm{PCl}$

\begin{tabular}{|c|c|c|c|}
\hline & $\begin{array}{c}\text { Cardiogenic } \\
\text { Shock group } \\
\quad(n=636)\end{array}$ & $\begin{array}{l}\text { Non-Cardiogenic } \\
\text { Shock group } \\
(n=12,548)\end{array}$ & $P$ value \\
\hline Age (years), mean $\pm S D$ & $66.36 \pm 12.23$ & $63.87 \pm 12.58$ & $<0.001$ \\
\hline Male, n (\%) & $461(72.5)$ & $9,488(75.6)$ & 0.073 \\
\hline $\mathrm{BMI} \mathrm{kg} / \mathrm{m}^{2}$, mean $\pm \mathrm{SD}$ & $27.38 \pm 5.19$ & $28.26 \pm 5.30$ & $<0.001$ \\
\hline Diabetes mellitus, n (\%) & $159(25.2)$ & $2,851(22.7)$ & 0.15 \\
\hline \multicolumn{4}{|l|}{ Diabetic status, n (\%) } \\
\hline Non-diabetic & $473(74.8)$ & $9,692(77.3)$ & \multirow{3}{*}{0.089} \\
\hline Non-insulin dependent & $113(17.9)$ & $2,185(17.4)$ & \\
\hline Insulin dependent & $46(7.3)$ & $666(5.3)$ & \\
\hline Hypertension, n (\%) & $379(60)$ & $7,760(61.9)$ & 0.33 \\
\hline Dyslipidemia, n (\%) & 309 (49.5) & $8,088(64.6)$ & $<0.001$ \\
\hline Ever smoked, n (\%) & $366(60.6)$ & $8,500(68.0)$ & $<0.001$ \\
\hline $\begin{array}{l}\text { Previous cerebrovascular disease, } \mathrm{n} \\
\text { (\%) }\end{array}$ & $48(7.6)$ & $773(6.2)$ & 0.14 \\
\hline Peripheral vascular disease, n (\%) & $53(8.4)$ & $734(5.9)$ & 0.008 \\
\hline Atrial Fibrillation, n (\%) & $80(16.1)$ & $465(5.0)$ & $<0.001$ \\
\hline $\begin{array}{l}\text { Family history of coronary disease, } \\
\mathrm{n}(\%)\end{array}$ & $128(21.1)$ & $4,792(38.6)$ & $<0.001$ \\
\hline $\begin{array}{l}\text { Previous myocardial infarction, } \mathrm{n} \\
\text { (\%) }\end{array}$ & $118(18.7)$ & $2,678(21.4)$ & 0.11 \\
\hline Prior PCl, n (\%) & $86(13.5)$ & $2,282(18.2)$ & 0.003 \\
\hline Prior CABG, n (\%) & $38(6)$ & $849(6.8)$ & 0.43 \\
\hline \multicolumn{4}{|l|}{ GFR mL/min/1.73m², n (\%) } \\
\hline$\geq 60$ & $256(42.6)$ & $9,581(78.3)$ & \multirow{3}{*}{$<0.001$} \\
\hline $30-59$ & $282(46.8)$ & 2,296 (18.8) & \\
\hline$<30$ & $65(10.8)$ & $361(3)$ & \\
\hline Dialysis requiring, $\mathrm{n}(\%)$ & $14(2.2)$ & $160(1.3)$ & 0.044 \\
\hline \multicolumn{4}{|l|}{ LVEF, n (\%) } \\
\hline$>45$ & 165 (31.3) & $8,113(71.9)$ & \multirow{3}{*}{$<0.001$} \\
\hline $30-45$ & $259(49.2)$ & $2,940(26.1)$ & \\
\hline$<30$ & 103 (19.5) & $224(2)$ & \\
\hline OHCA, n (\%) & 198 (31.1) & $275(2.2)$ & $<0.001$ \\
\hline \multicolumn{4}{|l|}{ ACS type, n (\%) } \\
\hline Unstable Angina & $3(0.5)$ & $1,908(15.2)$ & \multirow{3}{*}{$<0.001$} \\
\hline NSTEMI & $67(10.5)$ & $5,240(41.8)$ & \\
\hline STEMI & $566(89)$ & $5,400(43.0)$ & \\
\hline
\end{tabular}


$\mathrm{PCl}$ indication for STEMI, $\mathrm{n}(\%)$

Primary $\mathrm{PCl}$

459 (78.6)

$3,881(35.8)$

$<0.001$

Post-thrombolysis

$55(8.7)$

$827(6.6)$

Rescue PCl

ACS, acute coronary syndrome; BMI, body mass index; CABG, coronary artery bypass graft; GFR, glomerular filtration rate; LVEF, left ventricular ejection fraction; NSTEMI, non-ST elevation myocardial infarction; OHCA, out of hospital cardiac arrest; $\mathrm{PCl}$, percutaneous coronary intervention; STEMI, ST-elevation myocardial infarction.

This article is protected by copyright. All rights reserved. 
Table 2. Procedural findings and characteristics of the two groups.

\begin{tabular}{|c|c|c|c|}
\hline & $\begin{array}{c}\text { Cardiogenic } \\
\text { Shock group } \\
\quad(n=636)\end{array}$ & $\begin{array}{c}\text { Non-Cardiogenic } \\
\text { Shock group } \\
(n=12,548)\end{array}$ & $P$ value \\
\hline $\begin{array}{l}\text { Congestive heart failure prior } \\
\text { to procedure, } \mathrm{n}(\%)\end{array}$ & $226(35.7)$ & $572(4.6)$ & $<0.001$ \\
\hline IABP, n (\%) & $371(58.3)$ & $99(0.8)$ & $<0.001$ \\
\hline Multivessel disease, n (\%) & 451 (70.9) & $7,057(56.5)$ & $<0.001$ \\
\hline $\begin{array}{l}\text { Left main coronary disease, } \\
\mathrm{n}(\%)\end{array}$ & $51(22.2)$ & $221(6.4)$ & $<0.001$ \\
\hline $\begin{array}{l}\text { STEMI DTBT } \leq 90 \text { minutes } \mathrm{n} \text {, } \\
(\%)\end{array}$ & $239(49.4)$ & $2,360(59)$ & $<0.001$ \\
\hline $\begin{array}{l}\text { STEMI DTBT in minutes, } \\
\text { median (IQR) }\end{array}$ & $90[60.0-120.5]$ & $79[50.0-114.0]$ & $<0.001$ \\
\hline $\begin{array}{l}\text { STEMI STBT in minutes, } \\
\text { median (IQR) }\end{array}$ & $192[145-286]$ & $206[148-324]$ & 0.036 \\
\hline $\mathrm{PCl}$ entry location, $\mathrm{n}(\%)$ & & & \\
\hline Radial & $17(2.7)$ & $1,431(11.4)$ & \multirow{3}{*}{$<0.001$} \\
\hline Femoral & $612(96.2)$ & $11,076(88.3)$ & \\
\hline Brachial & $7(1.1)$ & $40(0.3)$ & \\
\hline Heparin, n (\%) & $627(98.6)$ & $12,262(97.8)$ & 0.17 \\
\hline Bivalirudin, n (\%) & $4(0.7)$ & $175(1.5)$ & 0.092 \\
\hline P2Y12 inhibitors, n (\%) & $574(90.3)$ & $12,355(98.5)$ & $<0.001$ \\
\hline \multicolumn{4}{|l|}{$\begin{array}{l}\text { Type of coronary lesion, } n \\
(\%)\end{array}$} \\
\hline De novo & $756(93.8)$ & $13,910(94.6)$ & 0.22 \\
\hline Restenosis & 0 & $29(0.2)$ & \\
\hline In-stent restenosis & $50(6.2)$ & $771(5.2)$ & \\
\hline \multicolumn{4}{|l|}{ Culprit Lesion PCl } \\
\hline LMCA disease, n (\%) & $54(6.7)$ & $86(0.6)$ & $<0.001$ \\
\hline LAD, n (\%) & $333(41.3)$ & $5,039(34.3)$ & $<0.001$ \\
\hline $\mathrm{RCA}, \mathrm{n}(\%)$ & $246(30.5)$ & $4,931(33.5)$ & 0.079 \\
\hline LCx, n (\%) & $100(12.4)$ & $1,906(13)$ & 0.65 \\
\hline B2/C lesion type*, n (\%) & $629(78.0)$ & $8,524(57.9)$ & $<0.001$ \\
\hline Ostial lesion, n (\%) & $83(10.3)$ & $986(6.7)$ & $<0.001$ \\
\hline Bifurcation lesion, n (\%) & $93(11.4)$ & $1,584(10.8)$ & 0.49 \\
\hline Pre-stenosis\%, median (IQR) & $100[90-100]$ & $90[80-100]$ & $<0.001$ \\
\hline $\begin{array}{l}\text { Pre-procedure TIMI flow, } n \\
(\%)\end{array}$ & & & $<0.001$ \\
\hline
\end{tabular}




$\begin{array}{ccc}0 & 504(62.8) & 4,145(28.3) \\ 1 & 45(5.6) & 648(4.4) \\ 2 & 88(11) & 1,629(11.1) \\ 3 & 166(20.7) & 8,228(56.2)\end{array}$

Post-procedure TIMI flow, $\mathrm{n}$ (\%)

0
1
2
3
stent length $(\mathrm{mm})$,
aSD

Mean stent diameter ( $\mathrm{mm})$, mean (SD)

$48(6)$
$18(2.2)$
$53(6.6)$
$685(85.2)$

$18.1 \pm 5.35$

259 (1.8)

$66(0.5)$

$286(2)$

14,089 (95.8)

Mean stent length $(\mathrm{mm})$,

mean \pm SD

$17.5 \pm 5.55$

$<0.001$

$3.03 \pm 0.49$

$2.97 \pm 0.49$

0.004

No reflow, n (\%)

Transient

Persistent

$58(7.5)$

33 (4.3)

492 (3.6)

$<0.001$

Successful lesion

revascularization, $\mathrm{n}(\%)$

695 (89.9)

13,227 (96.8)

$<0.001$

Type of stents used, n (\%)

DES
BMS

146 (23)

$5,296(42.2)$

$<0.001$

420 (66)

$6,572(52.4)$

IVUS, n (\%)

$1(0.12)$

$125(0.9)$

0.025

Thrombectomy device, n (\%)

$161(24.7)$

$1,297(11.8)$

$<0.001$

BMS, bare metal stent; DES, drug eluting stent; DTBT, door-to-balloon time; IABP, intraaortic balloon pump; IVUS, intra-vascular ultrasound; LAD, left anterior descending; LCx, left circumflex; LMCA, left main coronary artery; RCA, right coronary artery; $\mathrm{PCl}$, percutaneous coronary intervention; STBT, symptom-to-balloon time; STEMI, ST-elevation myocardial infarction; TIMI, thrombolysis in myocardial infarction.

*Type B2/C lesion is based on the American College of Cardiology/American Heart Association classification of coronary lesions.

This article is protected by copyright. All rights reserved. 
Table 3. In-hospital, 30-Day and NDI-linked mortality in both groups.

\begin{tabular}{|c|c|c|c|}
\hline & $\begin{array}{l}\text { Cardiogenic Shock } \\
\text { Group }(n=636)\end{array}$ & $\begin{array}{l}\text { Non-Cardiogenic Shock } \\
\text { Group }(n=12,548)\end{array}$ & $P$ value \\
\hline \multicolumn{4}{|l|}{ In-Hospital Outcomes } \\
\hline Mortality, n (\%) & $257(40.4)$ & $146(1.2)$ & $<0.001$ \\
\hline Cardiac mortality, n (\%) & $223(87.1)$ & $110(75.3)$ & 0.003 \\
\hline MACE, n (\%) & $292(45.9)$ & $371(3)$ & $<0.001$ \\
\hline $\begin{array}{l}\text { Post-procedural } \\
\text { myocardial infarction, } \mathrm{n} \\
(\%)\end{array}$ & $26(4.1)$ & $115(0.9)$ & $<0.001$ \\
\hline Emergency PCI, n (\%) & $16(2.5)$ & $81(0.7)$ & $<0.001$ \\
\hline Unplanned CABG, n (\%) & $21(3.3)$ & $97(0.8)$ & $<0.001$ \\
\hline Stent thrombosis, n (\%) & $12(2.3)$ & $94(0.5)$ & $<0.001$ \\
\hline Arrhythmia, n (\%) & 367 (57.9) & 995 (7.9) & $<0.001$ \\
\hline CVA, n (\%) & $11(1.7)$ & $40(0.3)$ & $<0.001$ \\
\hline $\begin{array}{l}\text { Congestive heart failure } \\
\text { post-procedure, } \mathrm{n}(\%)\end{array}$ & 238 (37.5) & $446(3.6)$ & $<0.001$ \\
\hline $\begin{array}{l}\text { New renal impairment, } n \\
(\%)\end{array}$ & 109 (17.2) & $112(0.9)$ & $<0.001$ \\
\hline $\begin{array}{l}\text { In-hospital major bleeding, } \\
\mathrm{n}(\%)\end{array}$ & 109 (17.2) & $326(2.6)$ & $<0.001$ \\
\hline \multicolumn{4}{|l|}{ Bleeding site, n (\%) } \\
\hline $\begin{array}{l}\text { Percutaneous entry } \\
\text { site } \\
\text { Retroperitoneal } \\
\text { Other }\end{array}$ & $\begin{array}{c}24(22.2) \\
3(2.8) \\
81(75)\end{array}$ & $\begin{aligned} 112 & (35.4) \\
18 & (5.7) \\
186 & (58.9)\end{aligned}$ & 0.011 \\
\hline $\begin{array}{l}\text { Transfusion of blood } \\
\text { products required after } \\
\text { cath lab visit, } \mathrm{n}(\%)\end{array}$ & $68(66)$ & $113(43)$ & $<0.001$ \\
\hline Pseudoaneurysm, n (\%) & $5(0.8)$ & $43(0.3)$ & 0.07 \\
\hline $\begin{array}{l}\text { Length of stay, median } \\
\text { (IQR) in days }\end{array}$ & $6[3-14]$ & $4[3-5]$ & $<0.001$ \\
\hline \multicolumn{4}{|l|}{ 30-Day Outcomes } \\
\hline Mortality, n (\%) & $261(41)$ & $208(1.7)$ & $<0.001$ \\
\hline Cardiac mortality, n (\%) & $224(86.2)$ & 149 (71.6) & $<0.001$ \\
\hline $\begin{array}{l}\text { Recurrent myocardial } \\
\text { infarction, } \mathrm{n}(\%)\end{array}$ & $31(4.9)$ & $239(1.9)$ & $<0.001$ \\
\hline TVR, n (\%) & $43(6.8)$ & $289(2.3)$ & $<0.001$ \\
\hline TLR, n (\%) & $40(6.3)$ & $236(1.9)$ & $<0.001$ \\
\hline CVA, n (\%) & $12(1.9)$ & $62(0.5)$ & $<0.001$ \\
\hline Readmission, n (\%) & $81(21.5)$ & 1,627 (13.2) & $<0.001$ \\
\hline MACE, n (\%) & 301 (47.3) & $607(4.8)$ & $<0.001$ \\
\hline
\end{tabular}


CABG, coronary artery bypass graft; CVA, cerebrovascular accident; TLR, target lesion revascularization; TVR, target vessel revascularization; MACE, major adverse cardiac events; $\mathrm{PCl}$, percutaneous coronary intervention.

*The NDI-linked mortality median follow-up is 4.2 years [2.1-6.6].

This article is protected by copyright. All rights reserved. 
Table 4. Multivariable predictors of NDI-linked death in the cardiogenic shock cohort

\begin{tabular}{lccc} 
& HR & 95\% Cl & P value \\
\hline Ejection Fraction $<30 \%$ & 3.006 & $2.037-4.436$ & $<0.001$ \\
GFR $<30 \mathrm{~mL} / \mathrm{min}$ per $1.73 \mathrm{~m}^{2}$ & 2.562 & $1.702-3.859$ & $<0.001$ \\
GFR 30-59 mL/min per 1.73 $\mathrm{m}^{2}$ & 1.941 & $1.437-2.623$ & $<0.001$ \\
OHCA & 1.467 & $1.102-1.953$ & 0.009 \\
Diabetes & 1.444 & $1.086-1.920$ & 0.011 \\
Age & 1.027 & $1.015-1.040$ & $<0.001$
\end{tabular}

HR, hazard ratio; GFR, glomerular filtration rate; OHCA, out-of-hospital cardiac arrest.

This article is protected by copyright. All rights reserved. 
Table 5. Subgroup analysis of the cardiogenic shock cohort.

\begin{tabular}{|c|c|c|c|c|c|c|}
\hline & $\begin{array}{c}\text { Single-Vessel } \\
\text { PCI }\end{array}$ & $\begin{array}{c}\text { Multi-vessel } \\
\mathrm{PCl}\end{array}$ & $P$ value & No STEMI & STEMI & $P$ Value \\
\hline \multicolumn{7}{|c|}{ In-Hospital Outcomes } \\
\hline Mortality & $220(39.1)$ & $36(50.0)$ & 0.075 & $44(62.9)$ & $213(37.6)$ & $<0.001$ \\
\hline MACE & $251(44.6)$ & $40(55.6)$ & 0.078 & $48(68.6)$ & $244(43.1)$ & $<0.001$ \\
\hline \multicolumn{7}{|c|}{ 30-Day Outcomes } \\
\hline Mortality & $224(39.8)$ & $36(50.0)$ & 0.09 & $45(64.3)$ & $216(38.2)$ & $<0.001$ \\
\hline MACE & $259(46.0)$ & $41(56.9)$ & 0.08 & $49(70.0)$ & $252(44.5)$ & $<0.001$ \\
\hline $\begin{array}{l}\text { Long-term } \\
\text { NDI-linked } \\
\text { Mortality }\end{array}$ & $276(49.0)$ & $45(62.5)$ & 0.031 & $55(78.6)$ & $267(47.2)$ & $<0.001$ \\
\hline
\end{tabular}

This article is protected by copyright. All rights reserved. 


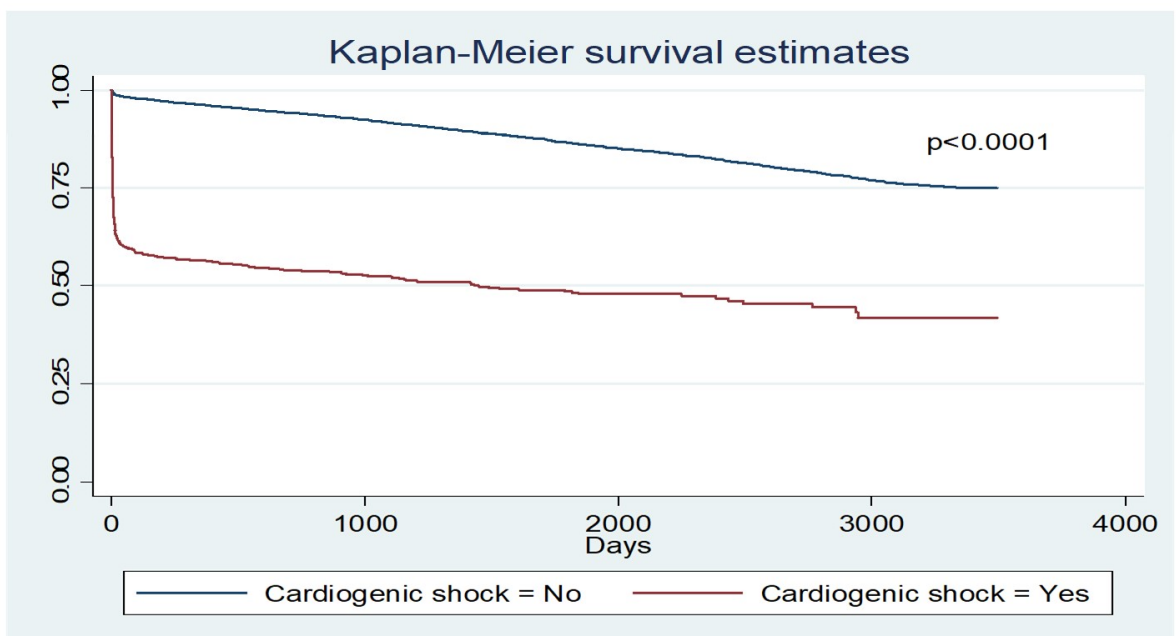

a
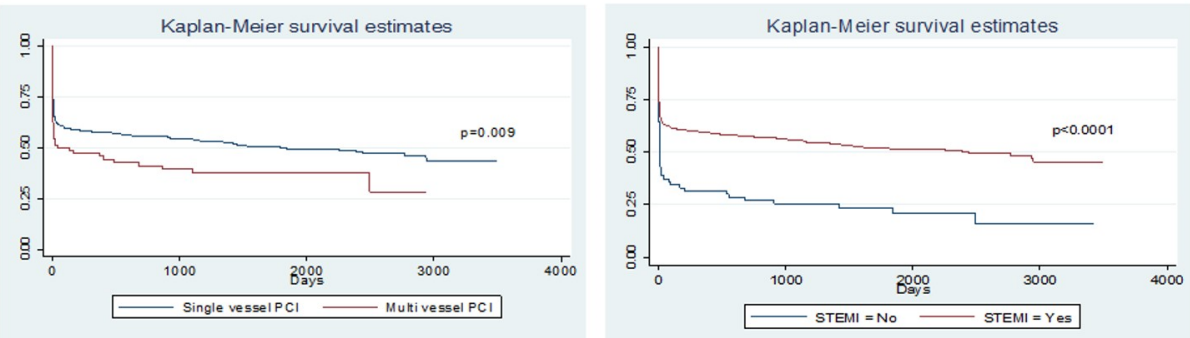

b

CCD_28759_Figure 1.tiff

This article is protected by copyright. All rights reserved. 


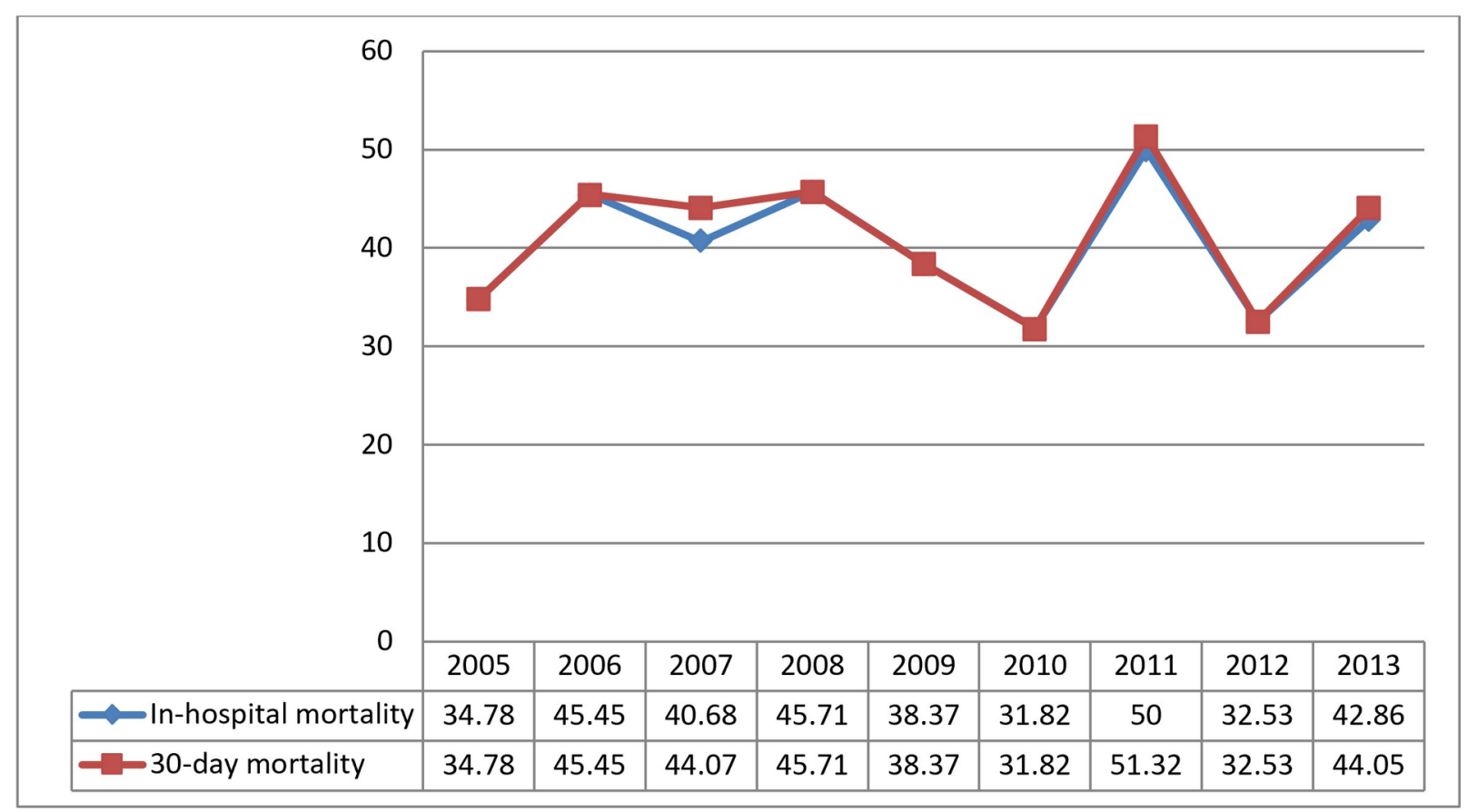

CCD_28759_Figure 2.tiff

This article is protected by copyright. All rights reserved. 


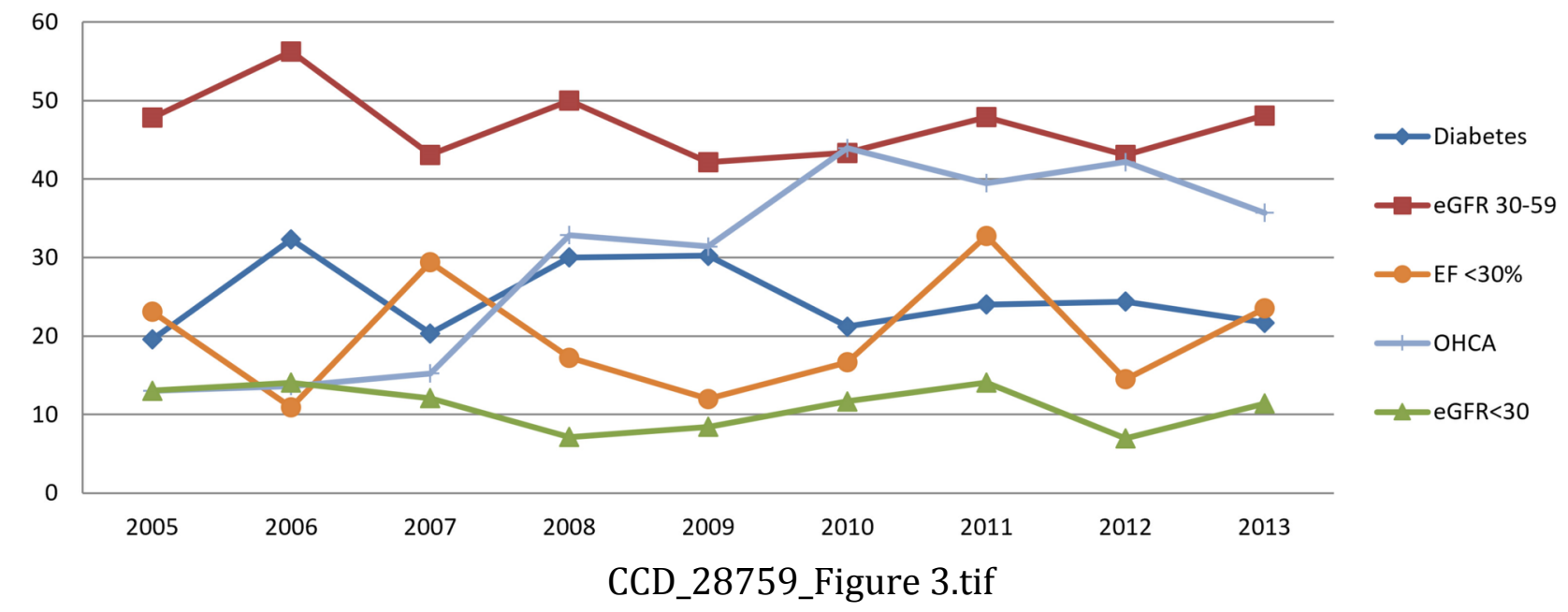

This article is protected by copyright. All rights reserved. 
Table 1. Baseline demographic and clinical characteristics of patients with ACS undergoing $\mathrm{PCl}$

\begin{tabular}{|c|c|c|c|}
\hline & $\begin{array}{c}\text { Cardiogenic } \\
\text { Shock group } \\
\quad(n=636)\end{array}$ & $\begin{array}{c}\text { Non-Cardiogenic } \\
\text { Shock group } \\
(n=12,548)\end{array}$ & $P$ value \\
\hline Age (years), mean \pm SD & $66.36 \pm 12.23$ & $63.87 \pm 12.58$ & $<0.001$ \\
\hline Male, n (\%) & $461(72.5)$ & $9,488(75.6)$ & 0.073 \\
\hline $\mathrm{BMI} \mathrm{kg} / \mathrm{m}^{2}$, mean $\pm \mathrm{SD}$ & $27.38 \pm 5.19$ & $28.26 \pm 5.30$ & $<0.001$ \\
\hline Diabetes mellitus, n (\%) & $159(25.2)$ & $2,851(22.7)$ & 0.15 \\
\hline \multicolumn{4}{|l|}{ Diabetic status, n (\%) } \\
\hline Non-diabetic & $473(74.8)$ & $9,692(77.3)$ & \multirow{3}{*}{0.089} \\
\hline Non-insulin dependent & $113(17.9)$ & $2,185(17.4)$ & \\
\hline Insulin dependent & $46(7.3)$ & $666(5.3)$ & \\
\hline Hypertension, n (\%) & $379(60)$ & $7,760(61.9)$ & 0.33 \\
\hline Dyslipidemia, n (\%) & $309(49.5)$ & $8,088(64.6)$ & $<0.001$ \\
\hline Ever smoked, n (\%) & $366(60.6)$ & $8,500(68.0)$ & $<0.001$ \\
\hline $\begin{array}{l}\text { Previous cerebrovascular disease, } \mathrm{n} \\
\text { (\%) }\end{array}$ & $48(7.6)$ & $773(6.2)$ & 0.14 \\
\hline Peripheral vascular disease, $\mathrm{n}(\%)$ & $53(8.4)$ & $734(5.9)$ & 0.008 \\
\hline Atrial Fibrillation, n (\%) & $80(16.1)$ & $465(5.0)$ & $<0.001$ \\
\hline $\begin{array}{l}\text { Family history of coronary disease, } \mathrm{n} \\
(\%)\end{array}$ & $128(21.1)$ & $4,792(38.6)$ & $<0.001$ \\
\hline Previous myocardial infarction, $\mathrm{n}(\%)$ & $118(18.7)$ & $2,678(21.4)$ & 0.11 \\
\hline Prior $\mathrm{PCl}, \mathrm{n}(\%)$ & $86(13.5)$ & $2,282(18.2)$ & 0.003 \\
\hline Prior CABG, n (\%) & $38(6)$ & $849(6.8)$ & 0.43 \\
\hline \multicolumn{4}{|l|}{ GFR mL/min/1.73m², n (\%) } \\
\hline$\geq 60$ & $256(42.6)$ & $9,581(78.3)$ & \multirow{3}{*}{$<0.001$} \\
\hline $30-59$ & $282(46.8)$ & $2,296(18.8)$ & \\
\hline$<30$ & $65(10.8)$ & $361(3)$ & \\
\hline Dialysis requiring, $\mathrm{n}(\%)$ & $14(2.2)$ & $160(1.3)$ & 0.044 \\
\hline \multicolumn{4}{|l|}{ LVEF, n (\%) } \\
\hline$>45$ & $165(31.3)$ & $8,113(71.9)$ & \multirow{3}{*}{$<0.001$} \\
\hline $30-45$ & $259(49.2)$ & $2,940(26.1)$ & \\
\hline$<30$ & $103(19.5)$ & $224(2)$ & \\
\hline OHCA, n (\%) & $198(31.1)$ & $275(2.2)$ & $<0.001$ \\
\hline \multicolumn{4}{|l|}{ ACS type, n (\%) } \\
\hline Unstable Angina & $3(0.5)$ & $1,908(15.2)$ & \multirow{3}{*}{$<0.001$} \\
\hline NSTEMI & $67(10.5)$ & $5,240(41.8)$ & \\
\hline STEMI & $566(89)$ & $5,400(43.0)$ & \\
\hline \multicolumn{4}{|l|}{ PCI indication for STEMI, n (\%) } \\
\hline Primary $\mathrm{PCl}$ & $459(78.6)$ & $3,881(35.8)$ & $<0.001$ \\
\hline Post-thrombolysis & $55(8.7)$ & $827(6.6)$ & 0.042 \\
\hline Rescue PCl & $36(65.5)$ & $252(30.5)$ & $<0.001$ \\
\hline
\end{tabular}

ACS, acute coronary syndrome; BMI, body mass index; CABG, coronary artery bypass graft; GFR, glomerular filtration rate; LVEF, left ventricular ejection fraction; NSTEMI, non-ST 
elevation myocardial infarction; OHCA, out of hospital cardiac arrest; $\mathrm{PCl}$, percutaneous coronary intervention; STEMI, ST-elevation myocardial infarction.

This article is protected by copyright. All rights reserved. 
Table 2. Procedural findings and characteristics of the two groups.

\begin{tabular}{|c|c|c|c|}
\hline & $\begin{array}{c}\text { Cardiogenic } \\
\text { Shock group } \\
(n=636)\end{array}$ & $\begin{array}{c}\text { Non-Cardiogenic } \\
\text { Shock group } \\
(n=12,548)\end{array}$ & $P$ value \\
\hline $\begin{array}{l}\text { Congestive heart failure prior } \\
\text { to procedure, } \mathrm{n}(\%)\end{array}$ & $226(35.7)$ & $572(4.6)$ & $<0.001$ \\
\hline IABP, n (\%) & $371(58.3)$ & $99(0.8)$ & $<0.001$ \\
\hline Multivessel disease, n (\%) & $451(70.9)$ & $7,057(56.5)$ & $<0.001$ \\
\hline $\begin{array}{l}\text { Left main coronary disease, } \mathrm{n} \\
(\%)\end{array}$ & $51(22.2)$ & $221(6.4)$ & $<0.001$ \\
\hline $\begin{array}{l}\text { STEMI DTBT } \leq 90 \text { minutes } \mathrm{n} \text {, } \\
(\%)\end{array}$ & $239(49.4)$ & $2,360(59)$ & $<0.001$ \\
\hline $\begin{array}{l}\text { STEMI DTBT in minutes, } \\
\text { median (IQR) }\end{array}$ & $90[60.0-120.5]$ & $79[50.0-114.0]$ & $<0.001$ \\
\hline $\begin{array}{l}\text { STEMI STBT in minutes, } \\
\text { median (IQR) }\end{array}$ & $192[145-286]$ & $206[148-324]$ & 0.036 \\
\hline \multicolumn{4}{|l|}{$\mathrm{PCl}$ entry location, $\mathrm{n}(\%)$} \\
\hline Radial & $17(2.7)$ & $1,431(11.4)$ & \multirow{3}{*}{$<0.001$} \\
\hline Femoral & $612(96.2)$ & $11,076(88.3)$ & \\
\hline Brachial & $7(1.1)$ & $40(0.3)$ & \\
\hline Heparin, n (\%) & $627(98.6)$ & $12,262(97.8)$ & 0.17 \\
\hline Bivalirudin, n (\%) & $4(0.7)$ & $175(1.5)$ & 0.092 \\
\hline P2Y12 inhibitors, n (\%) & $574(90.3)$ & $12,355(98.5)$ & $<0.001$ \\
\hline \multicolumn{4}{|l|}{$\begin{array}{l}\text { Type of coronary lesion, } n \\
\text { (\%) }\end{array}$} \\
\hline De novo & $756(93.8)$ & $13,910(94.6)$ & 0.22 \\
\hline Restenosis & 0 & $29(0.2)$ & \\
\hline In-stent restenosis & $50(6.2)$ & $771(5.2)$ & \\
\hline \multicolumn{4}{|l|}{ Culprit Lesion PCl } \\
\hline LMCA disease, n (\%) & $54(6.7)$ & $86(0.6)$ & $<0.001$ \\
\hline LAD, n (\%) & $333(41.3)$ & $5,039(34.3)$ & $<0.001$ \\
\hline RCA, n (\%) & $246(30.5)$ & $4,931(33.5)$ & 0.079 \\
\hline LCx, n (\%) & $100(12.4)$ & $1,906(13)$ & 0.65 \\
\hline B2/C lesion type*, n (\%) & $629(78.0)$ & $8,524(57.9)$ & $<0.001$ \\
\hline Ostial lesion, n (\%) & $83(10.3)$ & $986(6.7)$ & $<0.001$ \\
\hline Bifurcation lesion, n (\%) & $93(11.4)$ & $1,584(10.8)$ & 0.49 \\
\hline Pre-stenosis\%, median (IQR) & $100[90-100]$ & $90[80-100]$ & $<0.001$ \\
\hline \multicolumn{4}{|l|}{$\begin{array}{l}\text { Pre-procedure TIMI flow, } \mathrm{n} \\
(\%)\end{array}$} \\
\hline 0 & $504(62.8)$ & $4,145(28.3)$ & \multirow{4}{*}{$<0.001$} \\
\hline 1 & $45(5.6)$ & $648(4.4)$ & \\
\hline 2 & $88(11)$ & $1,629(11.1)$ & \\
\hline 3 & $166(20.7)$ & $8,228(56.2)$ & \\
\hline $\begin{array}{l}\text { Post-procedure TIMI flow, } \mathrm{n} \\
(\%)\end{array}$ & & & $<0.001$ \\
\hline
\end{tabular}


Mean stent length (mm), mean $\pm S D$

Mean stent diameter $(\mathrm{mm})$, mean (SD)

No reflow, $\mathrm{n}(\%)$

Transient

Persistent

Successful lesion

revascularization, $\mathrm{n}(\%)$

Type of stents used, $\mathrm{n}(\%)$

DES

BMS

IVUS, n (\%)

Thrombectomy device, n (\%)
$48(6)$

$18(2.2)$

$53(6.6)$

$685(85.2)$

$18.1 \pm 5.35$

$3.03 \pm 0.49$

$2.97 \pm 0.49$

0.004

$58(7.5)$

$33(4.3)$

695 (89.9)

$13,227(96.8)$

$<0.001$

146 (23)

$420(66)$

$5,296(42.2)$

$6,572(52.4)$

$1(0.12)$

$125(0.9)$

0.025

$161(24.7)$

$<0.001$

BMS, bare metal stent; DES, drug eluting stent; DTBT, door-to-balloon time; IABP, intra-aortic balloon pump; IVUS, intra-vascular ultrasound; LAD, left anterior descending; LCX, left circumflex; LMCA, left main coronary artery; RCA, right coronary artery; PCl, percutaneous coronary intervention; STBT, symptom-to-balloon time; STEMI, ST-elevation myocardial infarction; TIMI, thrombolysis in myocardial infarction.

*Type B2/C lesion is based on the American College of Cardiology/American Heart Association classification of coronary lesions. 
Table 3. In-hospital, 30-Day and NDI-linked mortality in both groups.

\begin{tabular}{|c|c|c|c|}
\hline & $\begin{array}{l}\text { Cardiogenic Shock } \\
\text { Group }(n=636)\end{array}$ & $\begin{array}{l}\text { Non-Cardiogenic Shock } \\
\text { Group }(n=12,548)\end{array}$ & $P$ value \\
\hline \multicolumn{4}{|l|}{ In-Hospital Outcomes } \\
\hline Mortality, n (\%) & $257(40.4)$ & $146(1.2)$ & $<0.001$ \\
\hline Cardiac mortality, n (\%) & $223(87.1)$ & $110(75.3)$ & 0.003 \\
\hline MACE, n (\%) & $292(45.9)$ & $371(3)$ & $<0.001$ \\
\hline $\begin{array}{l}\text { Post-procedural } \\
\text { myocardial infarction, n } \\
(\%)\end{array}$ & $26(4.1)$ & $115(0.9)$ & $<0.001$ \\
\hline Emergency $\mathrm{PCl}, \mathrm{n}(\%)$ & $16(2.5)$ & $81(0.7)$ & $<0.001$ \\
\hline Unplanned CABG, n (\%) & $21(3.3)$ & $97(0.8)$ & $<0.001$ \\
\hline Stent thrombosis, n (\%) & $12(2.3)$ & $94(0.5)$ & $<0.001$ \\
\hline Arrhythmia, n (\%) & 367 (57.9) & $995(7.9)$ & $<0.001$ \\
\hline CVA, n (\%) & $11(1.7)$ & $40(0.3)$ & $<0.001$ \\
\hline $\begin{array}{l}\text { Congestive heart failure } \\
\text { post-procedure, } n(\%)\end{array}$ & $238(37.5)$ & $446(3.6)$ & $<0.001$ \\
\hline $\begin{array}{l}\text { New renal impairment, } n \\
(\%)\end{array}$ & $109(17.2)$ & $112(0.9)$ & $<0.001$ \\
\hline $\begin{array}{l}\text { In-hospital major bleeding, } \\
\mathrm{n}(\%)\end{array}$ & 109 (17.2) & $326(2.6)$ & $<0.001$ \\
\hline \multicolumn{4}{|l|}{ Bleeding site, $\mathrm{n}(\%)$} \\
\hline $\begin{array}{l}\text { Percutaneous entry } \\
\text { site } \\
\text { Retroperitoneal } \\
\text { Other }\end{array}$ & $\begin{array}{c}24(22.2) \\
3(2.8) \\
81(75)\end{array}$ & $\begin{aligned} 112 & (35.4) \\
18 & (5.7) \\
186 & (58.9)\end{aligned}$ & 0.011 \\
\hline $\begin{array}{l}\text { Transfusion of blood } \\
\text { products required after } \\
\text { cath lab visit, } \mathrm{n}(\%)\end{array}$ & $68(66)$ & $113(43)$ & $<0.001$ \\
\hline Pseudoaneurysm, n (\%) & $5(0.8)$ & $43(0.3)$ & 0.07 \\
\hline $\begin{array}{l}\text { Length of stay, median } \\
\text { (IQR) in days }\end{array}$ & $6[3-14]$ & $4[3-5]$ & $<0.001$ \\
\hline \multicolumn{4}{|l|}{ 30-Day Outcomes } \\
\hline Mortality, n (\%) & $261(41)$ & $208(1.7)$ & $<0.001$ \\
\hline Cardiac mortality, n (\%) & $224(86.2)$ & $149(71.6)$ & $<0.001$ \\
\hline $\begin{array}{l}\text { Recurrent myocardial } \\
\text { infarction, } n(\%)\end{array}$ & $31(4.9)$ & $239(1.9)$ & $<0.001$ \\
\hline TVR, n (\%) & $43(6.8)$ & $289(2.3)$ & $<0.001$ \\
\hline TLR, n (\%) & $40(6.3)$ & $236(1.9)$ & $<0.001$ \\
\hline CVA, n (\%) & $12(1.9)$ & $62(0.5)$ & $<0.001$ \\
\hline Readmission, n (\%) & $81(21.5)$ & $1,627(13.2)$ & $<0.001$ \\
\hline MACE, n (\%) & 301 (47.3) & $607(4.8)$ & $<0.001$ \\
\hline $\begin{array}{l}\text { NDI-linked mortality }{ }^{*} \text { n } \\
(\%)\end{array}$ & $322(50.6)$ & $1,734(13.8)$ & $<0.001$ \\
\hline
\end{tabular}

CABG, coronary artery bypass graft; CVA, cerebrovascular accident; TLR, target lesion revascularization; TVR, target vessel revascularization; MACE, major adverse cardiac events; $\mathrm{PCl}$, percutaneous coronary intervention.

*The NDI-linked mortality median follow-up is 4.2 years [2.1-6.6]. 
Table 4. Multivariable predictors of NDI-linked death in the cardiogenic shock cohort

\begin{tabular}{lccc} 
& HR & 95\% Cl & P value \\
\hline Ejection Fraction $<30 \%$ & 3.006 & $2.037-4.436$ & $<0.001$ \\
GFR $<30 \mathrm{~mL} / \mathrm{min}$ per $1.73 \mathrm{~m}^{2}$ & 2.562 & $1.702-3.859$ & $<0.001$ \\
GFR 30-59 mL/min per $1.73 \mathrm{~m}^{2}$ & 1.941 & $1.437-2.623$ & $<0.001$ \\
OHCA & 1.467 & $1.102-1.953$ & 0.009 \\
Diabetes & 1.444 & $1.086-1.920$ & 0.011 \\
Age & 1.027 & $1.015-1.040$ & $<0.001$ \\
\hline
\end{tabular}

HR, hazard ratio; GFR, glomerular filtration rate; OHCA, out-of-hospital cardiac arrest. 
Table 5. Subgroup analysis of the cardiogenic shock cohort.

\begin{tabular}{|c|c|c|c|c|c|c|}
\hline & $\begin{array}{c}\text { Single-Vessel } \\
\mathrm{PCl}\end{array}$ & $\begin{array}{l}\text { Multi-vessel } \\
\text { PCl }\end{array}$ & $P$ value & No STEMI & STEMI & P Value \\
\hline \multicolumn{7}{|c|}{ In-Hospital Outcomes } \\
\hline Mortality & 220 (39.1) & $36(50.0)$ & 0.075 & $44(62.9)$ & $213(37.6)$ & $<0.001$ \\
\hline MACE & 251 (44.6) & $40(55.6)$ & 0.078 & $48(68.6)$ & $244(43.1)$ & $<0.001$ \\
\hline \multicolumn{7}{|c|}{ 30-Day Outcomes } \\
\hline Mortality & 224 (39.8) & $36(50.0)$ & 0.09 & $45(64.3)$ & $216(38.2)$ & $<0.001$ \\
\hline MACE & $259(46.0)$ & $41(56.9)$ & 0.08 & $49(70.0)$ & $252(44.5)$ & $<0.001$ \\
\hline $\begin{array}{l}\text { Long-term } \\
\text { NDI-linked } \\
\text { Mortality }\end{array}$ & $276(49.0)$ & $45(62.5)$ & 0.031 & 55 (78.6) & $267(47.2)$ & $<0.001$ \\
\hline
\end{tabular}

This article is protected by copyright. All rights reserved. 


\section{University Library}

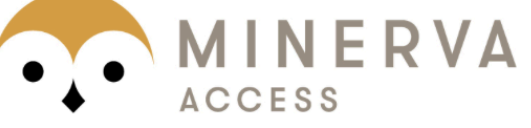

A gateway to Melbourne's research publications

Minerva Access is the Institutional Repository of The University of Melbourne

\section{Author/s:}

Noaman, S;Andrianopoulos, N;Brennan, AL;Dinh, D;Reid, C;Stub, D;Biswas, S;Clark, D;Shaw, J;Ajani, A;Freeman, M;Yip, T;Oqueli, E;Walton, A;Duffy, SJ;Chan, W

Title:

Outcomes of cardiogenic shock complicating acute coronary syndromes

Date:

2020-02-03

\section{Citation:}

Noaman, S., Andrianopoulos, N., Brennan, A. L., Dinh, D., Reid, C., Stub, D., Biswas, S., Clark, D., Shaw, J., Ajani, A., Freeman, M., Yip, T., Oqueli, E., Walton, A., Duffy, S. J. \& Chan, W. (2020). Outcomes of cardiogenic shock complicating acute coronary syndromes. CATHETERIZATION AND CARDIOVASCULAR INTERVENTIONS, 96 (3), pp.E257-E267. https://doi.org/10.1002/ccd.28759.

Persistent Link:

http://hdl.handle.net/11343/275357 